\title{
A Study on Maximization Paradox and Its Psychological Origin
}

\author{
Hao Ding, Aimei Li \\ School of Management, Jinan University, Guangzhou, China \\ Email: idinghao@163.com
}

How to cite this paper: Ding, H., \& Li, A. M. (2018). A Study on Maximization Paradox and Its Psychological Origin. Psychology, 9, 785-796.

https://doi.org/10.4236/psych.2018.94050

Received: March 14, 2018

Accepted: April 24, 2018

Published: April 27, 2018

Copyright $\odot 2018$ by authors and Scientific Research Publishing Inc. This work is licensed under the Creative Commons Attribution International License (CC BY 4.0).

http://creativecommons.org/licenses/by/4.0/

\section{c) (i) Open Access}

\begin{abstract}
Compared with satisficers, maximizers intend to pursue optimal results, leading to more negative emotions and worse experience. Even when they do get a better result, they are still less satisfied. We call it "maximization paradox". Theoretically, the purpose of this study is to enrich and deepen research in fields of the maximization paradox and its psychological origin. What's more, we intend to provide feasible advice for corporations and the government on the basis of our findings. By reviewing existing literatures, we find that the psychological origin of this paradox includes three aspects: the uncertainty of their optimal standards, their behavioral strategies to search and compare excessively, and more cognitive biases such as expectation biases and focusing biases. These conclusions help us to better understand the maximizing tendency and make relevant suggestions for decision-makers.
\end{abstract}

\section{Keywords}

Maximization Paradox, Decision Objective, Behavior Strategy, Cognitive Bias

\section{Introduction}

The material life of modern society is greatly enriched. More and more choices have not only brought people much more convenience but also brought more challenges to people, and there are more and more people get lost in a world with infinite choices. Selecting difficulties, paradox of choice, tyranny of choice etc. are all appropriate descriptions of a phenomenon that people have difficulties coping with a large number of choices and ultimately withstand the negative decisions of their decisions (Broniarczyk \& Griffin, 2014; Iyengar \& Lepper, 2000). And for this phenomenon, those who pursue the best in life are more likely to withstand the negative effects. Compared to those who pursue satisfactory, decision makers that pursue optimal decision outcome are paying more in 
the process of decision-making. But on the other hand, it appears that it is harder for them to reap better decision-making experience. They are more easily lost in a variety of choices. This phenomenon is called the paradox of maximization.

Rational Decision Model holds that individuals can be fully rational and maximize their utility (von Neumann \& Morgenstern, 1944). But the bounded rationality model (Simon, 1955; Simon, 1956; Simon, 1957), on the other hand, says that individuals are not able to be completely rational considering the limitations of individuals' information processing capabilities and the complexity of the environment. Corresponding to these two viewpoints, Schwartz et al. (2002) proposed maximization and satisfaction and used maximizer and satisficer to describe individuals with the above decision styles. In his opinion, maximizers are those who aim at maximizing utility, striving for excellence in decision-making, seeking to find the best choice, and obtaining optimal results. Meanwhile, satisficers are those who pursue something "good enough" and cease when they are satisfied. Previous studies have found that there are differences in decision-making characteristics and psychological indicators between maximizers and satisficers (Zhu \& Xie, 2013), including the searching tendencies and behaviors before making decisions (Schwartz, Ward, Monterosso, Lyubomirsky, White, \& Lehman, 2002), their models of comparative behavior (Iyengar, Wells, \& Schwartz, 2006) and reference objects (Weaver, Daniloski, Schwarz, \& Cottone, 2015) in decision-making, and decision-making experience both during and after the decision-making process (Ma \& Roese, 2014). In particular, compared to satisficers, maximizers experience more negative emotions in decision-making, and their satisfaction is lower even if they get better objective decision results. The inconsistency between decision-making outcomes and experiences is called as maximization paradox.

Maximization and paradox of maximization have caused widespread concern. The maximization paradox reflects the difference in decision-making quality and experience between maximizers and satisficers. The analysis of the psychological roots of this phenomenon helps to reveal the essential differences between maximizers and satisficers. This study will first sort out the existing definition and measurement methods of maximization, and then analyze the fundamental differences between the two types of decision-makers in decision-making goals, behavioral strategies and cognitive styles through the analysis of the psychological roots of maximization. At the end of the article, the direction of future research in this field and its practical application are discussed to provide new ideas for future research.

The current definitions and measures of maximization can be divided into two categories. The first category is represented by Schwartz et al. (2002). They describe the maximizing as "the desire to get only the best, with the tendency to search out and compare among alternatives and to find decisions stressful". The Maximization Scale (MS) was developed on the basis of this definition. Schwartz et al. (2002) believe the maximizing tendency consists of three dimensions (hav- 
ing high standards, seeking out and comparing among alternatives, and experiencing decision difficulty), and they use the total score of three factors as a measure of people's maximizing tendency. Contrary to this view, Diab, Gillespie, and Highhouse (2008) believe that the maximizing tendency is "the general tendency to pursue the identification of the optimal alternative" and put forward Maximizing Tendency Scale (MTS) containing only one factor.

Other researches either followed Schwartz et al. (2002)'s definition and measure, such as The Short Form of Maximization Scale created by Nenkov, Morrin, Ward, Schwartz and Hulland (2008) and Relational Maximization Scale created by Mikkelson and Pauley (2013); or followed the construction of Diab et al. (2008), for example, Modified Maximizing Scale of Lai (2010), 7-Item Maximizing Tendency Scale of Dalal et al. (2015). There are also definitions and measures which combine or split the three factors on the basis of Schwartz "s" construction. For example, Misuraca, Faraci, Gangemi, Carmeci and Miceli (2015) divided the maximizing tendency into resolute maximization and fearful maximization. The former mainly reflects the "having high standards" and "seeking out and comparing among alternative" in MS. The fearful optimization tendency mainly reflects the "experiencing decision difficulty" dimension. Besides, there are MS-R (Refined Maximization Scale) proposed by Richardson, Ye, Ege, Suh and Rice (2014). The "wanting the best" factor is similar to the "high standard" factor in the aforementioned scale. "Experiencing regret in decision making" is similar to items in MS reflecting "decision difficulty" and the ones in the regret scale. And decision difficulty "was mainly derived from the entries in" decision difficulty "and seeking out and comparing among alternatives" in MS.

\section{The Maximization Paradox}

A large number of studies have found that maximizers experience more negative emotions in the decision-making process and are less happy (Schwartz et al., 2002; Mikkelson \& Pauley, 2013; Cheek \& Schwartz, 2016). For instance, Schwartz et al. (2002) have found that the maximizing tendency is negatively correlated with positive psychological indicators (such as optimism and happiness) and positively correlated with negative psychological indicators (such as depression, regret, perfectionism, and low life satisfaction) using the Maximization Scale. Mikkelson and Pauley (2013) used the Relational Maximization Scale (RMS) to study the maximizing tendencies in the courtship and found that maximizers were more difficult to satisfy. It is more difficult for them to form a sense of dependency in romantic relationships and they are more likely to regret or change the initial decision.

In order to clarify the relationship between maximizing tendencies and negative emotions, researchers have also studied their relationships in different factors. The MS-S (Short Form of Maximization Scale) formed by Nenkov et al. (2008) named the three factors of MS as three distinct factors: having high standards, seeking out and comparing among alternatives, and experiencing decision 
difficulty. They have found that "seeking out and comparing among alternatives" is positively related to regret and negatively related to life satisfaction; "experiencing decision difficulty" is positively related to regrets, low life satisfaction, frustration and other indicators; "having high standards" is positively associated with perfectionism and regret, and is not related to depression, happiness, and life satisfaction. Nenkov et al. (2008) believe that the inadaptability of the maximizing tendency may be caused by the tendency to "seeking out and comparing among alternatives" and "experiencing decision difficulty", while the "having high standards" factor may be positive. Richardson et al. (2014) and Misuraca et al. (2015) studied the relationship between each factor of maximizing tendency and positive or negative emotion indicators, and the results also maintained certain consistency with the aforementioned researches. It is worth mentioning that there are researchers who have doubts about the proposition that "maximizers are less happy". Diab et al. (2008), for example, believes that the maximizers are not "more unhappy" than satisficers, and the conclusion that "maximizers are more unhappy" is caused by the inappropriate measurement method of Schwartz et al. (2002). Using Maximizing Tendency Scale, they find that the maximizing tendency is positively related to regret and has no significant correlation with other negative emotions. Weinhardt, Morse and Chimeli (2012) using the MTS-7 scale, Dalal et al. (2015) using the Revised Maximization Scale have also found that there was no significant correlation between the maximizing tendency and the negative emotions mentioned by Schwartz et al. (2002).

This study believes that the positive correlation between a single factor in maximizing tendency (such as "having high standards") and positive emotions may exist. But according to the theoretical origin and definition of maximizer (Simon, 1955; Simon, 1956; Simon, 1957; Schwartz et al., 2002), The connotation of the maximizing is more than "having high standards", a single factor (whether it's "having high standards", "seeking out and comparing among alternatives" or "experiencing decision difficulty") can't adequately cover the entire concept of maximizing. Therefore, the relationship between one single factor and people's psychological indicators cannot represent the overall relationship between maximizers' maximizing tendency and their emotions, neither positive nor negative. People's maximizing tendencies are positively correlated with their negative emotions (such as regret, frustration, etc.).

\section{The Psychological Roots of Maximization Paradox}

Compared to satisfcers, maximizers experience more negative emotions during their decision-making process, even if they get better results, they are less satisfied and their decision-making experience is worse. This phenomenon is called "maximization paradox". Researchers have found this phenomenon in all kinds of fields such as job search (Iyengar et al., 2006), romance (Mikkelson \& Pauley 2013), and consumption (Weaver et al., 2015; Shiner, 2016). The psychological 
roots of maximizing paradox reflect the essential difference between maximizers and satisficers in their goals, behaviors, and cognition styles related to decision-making. The psychological roots of maximizing paradox mainly include the following three aspects: 1) Their appraisal standard is uncertain; 2) Their excessive search and over-comparative behavioral strategies existing in the decision-making process; 3 ) There are more cognitive biases.

\subsection{Uncertain Appraisal Standards}

Ones' decision-making standards are related to their own conditions and situations. It is not an absolute thing. The difference between maximizers and satisficers is that that the "satisfaction" standard of satisficers is relatively fixed, while the "optimal" standard of maximizers is more uncertain. The uncertainty of the "optimal" standard is reflected in two points: 1) the "optimal" criteria for judgment before maximizers make their decisions are uncertain: as the number of options increases, the "optimal” criterion continues to increase; 2) maximizers' "optimal" evaluation criteria after they made their decision are uncertain, they are constantly changing and inconsistent with the criterion of what is "optimal" before the decision.

Maximizers always prefer more options. As the number of options increases, their subjective expectations for decision results increase (Iyengar et al., 2006): Researchers have found that maximizers are more proactive (relative to objective reality) in their prediction of decision-making outcomes and are "overconfident" with their own performance (Jain, Bearden, \& Filipowicz, 2011), which makes it easier for them to be blindly optimistic and set unrealistic goals. In addition, there may be options in the context of lower overall utility but better in one factor, the decision criteria of a maximizer will also increase with the appearance of such options. That will cause a constantly rising in utility of the "optimal choice" in the minds of maximizers. Contrary to the subjective expectations of decision-makers, the increase in options will increase the objective difficulty for individuals to achieve "the best" and individuals will find it more difficult to get a good experience.

On the other hand, there is greater uncertainty about the evaluation criteria of the "optimal" choice after maximizers made their decisions. At first, decision makers evaluate what is the best choice with the principle of maximizing overall utility (Schwartz et al., 2002; Mao, 2015). After the decision, they may compare the selected options with the unselected ones in one single factor which will cause changes in the evaluation criteria before and after the decision. In addition, maximizers pay more attention to relative standards and are more influenced by the external environment. When it is difficult to judge which choice is the best, they rely more on external (social comparison) criteria to make the decisions (Lyubomirsky \& Ross, 1998; Iyengar et al., 2006; Weaver et al., 2015). Compared to internal standards, external relative standards are more susceptible to the external environment and are therefore more unstable. 


\subsection{Over-Searching and Over-Comparing Behavioral Strategies}

Maximizers tend to pursue the best through an over-searching and over-comparing behavioral strategy (Schwartz et al., 2002; Dar-Nimrod, Rawn, Lehman, \& Schawartz, 2009). This behavioral strategy makes it more difficult for maximizers to make commitments and generate positive experiences (Sparks, Ehrlinger, \& Eibach, 2012). On the other hand, over-searching and over-comparing behavioral strategies increase the cost of decision-making and generate more negative emotions (Polman, 2010).

Over-searching and over-comparing behavioral strategies can influence maximizers' cognitive evaluation of "the best choice". Compared to satisficers, maximizers will conduct more social comparisons and counterfactual thinking both before and after the decision (Schwartz et al., 2002; Iyengar et al., 2006). This difference will affect the evaluation of the maximizers' appraisal of the selected options. Sparks et al. (2012) believe that the reason why it is difficult for maximizers to obtain a better decision experience and satisfaction with the decision is that they are focused on finding the optimal solution and thus avoiding the commitment to their choice. Generating commitment to choices that have been made is an important prerequisite for decision makers to generate positive psychological effects (Brehm \& Cohen, 1964; Brehm, 1966). Maximizers' behavioral strategies makes it difficult to generate a commitment to choices, and that make it even more difficult for them to get positive decision-making experiences (Sparks et al., 2012).

Over-searching and over-comparing behavioral strategies consume a lot of resources. With the depletion of resources, maximizers will generate more negative experiences such as feelings of inability, anxiety, fears of failure to achieve optimal, and regrets for giving up other excellent options (Iyengar et al., 2006; Chowdhury, Ratneshwar, \& Mohanty, 2009). In addition, while maximizers have gained more choices, there are certain costs. According to the Marginal Diminishing Effect, after a certain degree, the income will gradually decrease, and even produce more harm than good. With the application of network, individuals have the unlimited choices. Therefore, maximizers with an over-searching and over-comparing behavioral strategy will eventually pay a huge cost, and when the cost they paid does not bring corresponding benefits, the decision-making experience of the decision maker naturally deteriorates.

\subsection{Maximizers Have More Cognitive Biases}

Maximizers tend to search and process more information. Their cognitive burdens are much heavier and that makes them generate much more cognitive biases. There are two kinds of cognitive biases: First, the expectation deviation. It is difficult for the maximizers to correctly determine the costs and benefits. There are more expected deviation of the decision-making results, which will cause the expectation disqualification, affecting the decision-making experience and satisfaction. 
Maximizers have a greater cognitive burden in the decision-making process (Yang \& Chiou, 2010). As options increase, their ability to exclude irrelevant information is reduced, they tend to over-generalize and produce more cognitive biases, making it difficult to correctly assess decision-making costs and benefits (Besharat, Ladik, \& Carrillat, 2014). Researchers have found that maximizers tend to underestimate decision-making costs and overestimate decision-making gains (Botti \& Hsee, 2010; Jain et al., 2011; Misuraca \& Teuscher, 2013). Maximizers prefer a large set of options. Researches show that a large set of options will increase individual's expectation. When the result of the decision can't reach their expectation, the individual will have greater negative expectations disqualification. But on the other hand, when the result of the decision exceeds expectations, it can only bring smaller positive expectations disqualification for them, making the satisfaction of maximizers lower than those of satisficers (Diehl \& Lamberton, 2008).

The way maximizers use to evaluate their decision-making costs and benefits and decision-making consequences is like the "loss aversion" mode Tversky and Kahneman put forward in 1991 in the behavioral economics (Kruger, Wirtz, Van Boven, \& Altermatt, 2004; Polman, 2010). That is, in the decision-making process, instead of focusing on the decision-making gains, it focuses on the cost of decision-making and "effort spending"; Instead of focusing on positive decision-making results and experiences, they focus on negative decision-making results and experiences. For example, it is found that maximizers may produce better results while achieving better results (Parker, Bruine de Bruin, \& Fischhoff, 2007). Sending more resumes when you are looking for a job may make you get more offers, but it may also get you more rejections (Iyengar et al., 2006). Researchers believe that the positive psychological feelings caused by positive decision-making results may be offset by the negative psychological feelings produced by negative decision-making results and that will reduce decision makers' decision-making experience (Polman, 2010).

\section{Future Directions}

\subsection{Improve Measurement Tools for Maximizing Tendency}

Future research should begin to construct more accurate measurements of maximizing tendency. The existing research on the "goal" component of maximizing has been relatively mature. For instance, Dalal et al. (2015) MTS-7 have good psychometric attributes. In the meanwhile, some of the measurements measuring behavioral strategies are already somewhat out of date, such as an item in Schwartz et al. (2002)'s MS: when I listen to the radio in the car, even if I'm satisfied with the programs I'm listening to now, and I'll transfer to other channels to see if there are any better programs. Future studies should be devoted to construct more suitable measurements that are more in line with current social context. In the meanwhile, the existing studies did not pay enough attention to maximizers' cognitive characteristics, which is also something the 
future researches should focus on strengthening.

In addition, the existing measurement methods are mostly self-reported subjective scales. The context in the scale items which measures individuals' behavioral pattern and tendency is from their daily life. It can't capture the decision-maker's maximizing tendency in specific decision-making situation. Studies have shown that one's maximizing tendencies in specific contexts may be influenced by the decision-making situation (Carrillat et al., 2011). Therefore it is necessary to construct more sensitive and accurate measurement indicators. The information search tendency of decision makers in specific decision situations can be more directly and accurately reflected by objective behavior indicators. Future studies should attempt to construct behavioral and neural indicators of maximizing tendency and improve measurement accuracy.

\subsection{Explore the Factors That Influence Maximizer's Decision-Making Quality and Experience}

The factors affecting the decision-making quality and experience of maximizers mainly contain personality traits and situational factors. As for the former, researchers have found that maximizers are more neurotic (Purvis, Howell, \& Iyer, 2011). They are usually more relevant to perfectionism and are less open (Bruine de Bruin, Parker, \& Fischhoff, 2007). They are more competitive (Weaver et al., 2015); the latter includes decision visibility (Lin, 2015), decision-making context reversibility (Shiner, 2016), socio-cultural environment, and socio-economic level (Roets, Schwartz, \& Guan, 2012; Oishi, Tsutsui, Eggleston, \& Galinha, 2014) which all have an impact on ones' decision-making style and their experiences. Datu (2015) found that in the cultural context of collectivism, maximizing tendency can make people with positive emotions more aware of the meaning of life. Researchers also found that changing the contextual factors can even change the individual's maximizing tendency to some extent (Carrillat, Ladik, \& Legoux, 2011). The characteristics of the decision makers themselves and the environment will have an important influence on the quality and experience of one's decision. "Better result but worse experience"-why this phenomenon, "maximizing paradox" happens, happened to whom, and in what kind of situation did it happen? This is a dilemma that future research should focus on.

\subsection{Exploring the Black Box of Cognitive Processing Model for Decision-Makers}

Simon (1955) and Schwartz et al. (2002) believe that both maximizers and satisficers calculate and compare the utility of the options, the only difference is that the standards for them are different: one pursues "best" while the other pursues "good enough". maximizers intend to analyze the utility of each factor of the option and pursue the maximization of the overall utility. This cognitive processing method is consistent with its decision-making behavior. Similarly, researchers believe that satisfied decision makers are also calculating the overall utility, and then choose the first option that meets the minimum threshold of their "good 
enough" utility range.

However, some studies have found that the total utility of options may not be the only evaluation indicator in the information processing of satisficers. For example, Mao (2015) found that different from maximizers (using the total utility as index, if there is no obvious optimal option, they will choose the option which is "OK" in all factors), the satisficers will focus more on one single factor which they think is the most important one. In other words, when forced selection must be made between total utility and target utility, satisfied decision makers may pay more attention to the quality of the target factor. Satisficers may heuristically process the options with clues to pros and cons in the decision-making process. And there may also be a chance that they use both analytical processing and heuristic-dynamic cognitive processing methods to make a choice. This may be the reason why satisficers have higher adaptability and satisfaction in decision-making. The black box of maximizers' and satisicers' decision-making process is worth further explored

\section{Conclusion}

In an attempt to clarify the contradictory literature on maximization paradox, we reviewed the published articles about maximizing tendency and the maximization paradox, striving to highlight the psychological roots that cause the maximization paradox. We then found that the psychological origin of this paradox included three aspects: the uncertainty of their optimal standards, their behavioral strategies to search and compare excessively, and more cognitive biases such as expectation biases and focusing biases. We hope that this review has helped create a clearer path for future research, and that we are now one step closer to maximizing the study of maximization.

\section{References}

Besharat, A., Ladik, D. M., \& Carrillat, F. A. (2014). Are Maximizers Blind to the Future? When Today's Best Does Not Make for a Better Tomorrow. Marketing Letters, 25, 77-91. https://doi.org/10.1007/s11002-013-9243-4

Botti, S., \& Hsee, C. K. (2010). Dazed and Confused by Choice: How the Temporal Costs of Choice Freedom Lead to Undesirable Outcomes. Organizational Behavior \& Human Decision Processes, 112, 161-171. https://doi.org/10.1016/j.obhdp.2010.03.002

Brehm, J. W. (1966). A Theory of Psychological Reactance. New York, NY: Academic Press.

Brehm, J. W., \& Cohen, A. R. (1964). Explorations in Cognitive Dissonance. American Catholic Sociological Review.

Broniarczyk, S. M., \& Griffin, J. G. (2014). Decision Difficulty in the Age of Consumer Empowerment. Journal of Consumer Psychology, 24, 608-625.

https://doi.org/10.1016/j.jcps.2014.05.003

Bruine de Bruin, W., Parker, A. M., \& Fischhoff, B. (2007). Individual Differences in Adult Decision-Making Competence. Journal of Personality and Social Psychology, 92, 938-956. https://doi.org/10.1037/0022-3514.92.5.938

Carrillat, F. A., Ladik, D. M., \& Legoux, R. (2011). When the Decision Ball Keeps Rolling: 
An Investigation of the Sisyphus Effect among Maximizing Consumers. Marketing Letters, 22, 283-296. https://doi.org/10.1007/s11002-010-9125-y

Cheek, N. N., \& Schwartz, B. (2016). On the Meaning and Measurement of Maximization. Judgment \& Decision Making, 11, 126-146.

Chowdhury, T. G., Ratneshwar, S., \& Mohanty, P. (2009). The Time-Harried Shopper: Exploring the Differences between Maximizers and Satisficers. Marketing Letters, 20, 155-167. https://doi.org/10.1007/s11002-008-9063-0

Dalal, D. K., Diab, D. L., Zhu, X., \& Hwang, T. (2015). Understanding the Construct of Maximizing Tendency: A Theoretical and Empirical Evaluation. Journal of Behavioral Decision Making, 28, 437-450. https://doi.org/10.1002/bdm.1859

Dar-Nimrod, I., Rawn, C. D., Lehman, D. R., \& Schwartz, B. (2009). The Maximization Paradox: The Costs of Seeking Alternatives. Personality \& Individual Differences, 46, 631-635. https://doi.org/10.1016/j.paid.2009.01.007

Datu, J. A. D. (2015). The Synergistic Interplay between Positive Emotions and Maximization Enhances Meaning in Life: A Study in a Collectivist Context. Current Psychology, $1-14$.

Diab, D. L., Gillespie, M. A., \& Highhouse, S. (2008). Are Maximizers Really Unhappy? The Measurement of Maximizing Tendency. Judgment and Decision Making, 3, 364-370.

Diehl, K., \& Lamberton, C. P. (2008). Great Expectations? Assortment Size, Expectations and Satisfaction. Journal of Marketing Research, 47, 312-322. https://doi.org/10.1509/jmkr.47.2.312

Iyengar, S. S., \& Lepper, M. R. (2000). When Choice Is De-Motivating: Can One Desire Too Much of a Good Thing? Journal of Personality \& Social Psychology, 79, 995-1006. https://doi.org/10.1037/0022-3514.79.6.995

Iyengar, S. S., Wells, R. E., \& Schwartz, B. (2006). Doing Better But Feeling Worse. Psychological Science, 17, 143-150. https://doi.org/10.1111/j.1467-9280.2006.01677.x

Jain, K., Bearden, J. N., \& Filipowicz, A. (2011). Do Maximizers Predict Better than Satisficers? Journal of Behavioral Decision Making, 26, 41-50. https://doi.org/10.1002/bdm.763

Kruger, J., Wirtz, D., Van Boven, L., \& Altermatt, T. W. (2004). The Effort Heuristic. Journal of Experimental Social Psychology, 40, 91-98. https://doi.org/10.1016/S0022-1031(03)00065-9

Lai, L. (2010). Maximizing without Difficulty: A Modified Maximizing Scale and Its Correlates. Judgment \& Decision Making, 5, 164-175.

Lin, H. C. (2015). Moderating Roles on Individuals' Decisions When Making Choices for Others. Food Quality \& Preference, 39, 221-227. https://doi.org/10.1016/j.foodqual.2014.07.017

Lyubomirsky, S., \& Ross, L. (1998). Hedonic Consequences of Social Comparison: A Contrast of Happy and Unhappy People. Journal of Personality \& Social Psychology, 73, 1141-1157. https://doi.org/10.1037/0022-3514.73.6.1141

Ma, J., \& Roese, N. J. (2014). The Maximizing Mind-Set. Journal of Consumer Research, 41, 71-92. https://doi.org/10.1086/674977

Mao, W. (2015). When One Desires Too Much of a Good Thing: The Compromise Effect under Maximizing Tendencies. Journal of Consumer Psychology, 26, 66-80. https://doi.org/10.1016/j.jcps.2015.04.007

Mikkelson, A. C., \& Pauley, P. M. (2013). Maximizing Relationship Possibilities: Relational Maximization in Romantic Relationships. Journal of Social Psychology, 153, 
467-485. https://doi.org/10.1080/00224545.2013.767776

Misuraca, R., \& Teuscher, U. (2013). Time Flies When You Maximize-Maximizers and Satisficers Perceive Time Differently When Making Decisions. Acta Psychologica, 143, 176-180.

Misuraca, R., Faraci, P., Gangemi, A., Carmeci, F. A., \& Miceli, S. (2015). The Decision Making Tendency Inventory: A New Measure to Assess Maximizing, Satisficing, and Minimizing. Personality \& Individual Differences, 85, 111-116. https://doi.org/10.1016/j.paid.2015.04.043

Nenkov, G. Y., Morrin, M., Ward, A., Schwartz, B., \& Hulland, J. (2008). A Short Form of the Maximization Scale: Factor Structure, Reliability and Validity Studies. Judgment and Decision Making, 3, 371-388.

Oishi, S., Tsutsui, Y., Eggleston, C., \& Galinha, I. C. (2014). Are Maximizers Unhappier than Satisficers? A Comparison between Japan and the USA. Journal of Research in Personality, 49, 14-20. https://doi.org/10.1016/j.jrp.2013.12.001

Parker, A. M., Bruine de Bruin, W., \& Fischhoff, B. (2007). Maximizers versus Satisficers: Decision-Making Styles, Competence, and Outcomes. Judgment and Decision Making, 2, 342-350.

Polman, E. (2010). Why Are Maximizers Less Happy than Satisficers? Because They Maximize Positive and Negative Outcomes. Journal of Behavioral Decision Making, 23, 179-190. https://doi.org/10.1002/bdm.647

Purvis, A., Howell, R. T., \& Iyer, R. (2011). Exploring the Role of Personality in the Relationship between Maximization and Well-Being. Personality and Individual Differences, 50, 370-375. https://doi.org/10.1016/j.paid.2010.10.023

Richardson, C. M. E., Ye, H. J., Ege, E., Suh, H., \& Rice, K. G. (2014). Refining the Measurement of Maximization: Gender Invariance and Relation to Psychological Well-Being. Personality \& Individual Differences, 70, 229-234.

https://doi.org/10.1016/j.paid.2014.06.048

Roets, A., Schwartz, B., \& Guan, Y. (2012). The Tyranny of Choice: A Cross-Cultural Investigation of Maximizing-Satisfising Effects on Well-Being. Judgment \& Decision Making, 7, 689-704.

Schwartz, B., Ward, A., Monterosso, J., Lyubomirsky, S., White, K., \& Lehman, D. R. (2002). Maximizing versus Satisficing: Happiness Is a Matter of Choice. Journal of Personality and Social Psychology, 83, 1178-1197. https://doi.org/10.1037/0022-3514.83.5.1178

Shiner, R. L. (2016). Maximizers, Satisficers, and Their Satisfaction with and Preferences for Reversible versus Irreversible Decisions. Social Psychological \& Personality Science, 6, 896-903.

Simon, H. A. (1955). A Behavioral Model of Rational Choice. Quarterly Journal of Economics, 69, 99-118. https://doi.org/10.2307/1884852

Simon, H. A. (1956). Rational Choice and the Structure of the Environment. Psychological Review, 63, 129-138. https://doi.org/10.1037/h0042769

Simon, H. A. (1957). Models of Man, Social and Rational: Mathematical Essays on Rational Human Behavior in Society Setting. New York, NY: Wiley.

Sparks, E. A., Ehrlinger, J., \& Eibach, R. P. (2012). Failing to Commit: Maximizers Avoid Commitment in a Way That Contributes to Reduced Satisfaction. Personality and Individual Differences, 52, 72-77. https://doi.org/10.1016/j.paid.2011.09.002

Von Neumann, J., \& Morgenstern, O. (1944). Theory of Games and Economic Behavior. Princeton, NJ: Princeton University Press. 
Weaver, K., Daniloski, K., Schwarz, N., \& Cottone, K. (2015). The Role of Social Comparison for Maximizers and Satisficers: Wanting the Best or Wanting to Be the Best? Journal of Consumer Psychology, 25, 372-388.

Weinhardt, J. M., Morse, B. J., \& Chimeli, J. (2012). An Item Response Theory and Factor Analytic Examination of Two Prominent Maximizing Tendency Scales. Judgment \& Decision Making, 7, 644-658.

Yang, M. L., \& Chiou, W. B. (2010). Looking Online for the Best Romantic Partner Reduces Decision Quality: The Moderating Role of Choice-Making Strategies. Cyberpsychology, Behavior, and Social Networking, 13, 207-210.

https://doi.org/10.1089/cyber.2009.0208

Zhu, D., \& Xie, X. (2013). Which One Is Better, Maximizing or Satisficing? Advances in Psychological Science, 21, 309-316. https://doi.org/10.3724/SP.J.1042.2013.00309 